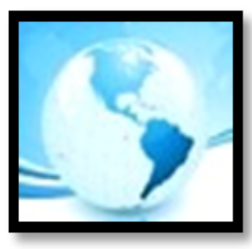

MALAYSIAN ONLINE JOURNAL OF

EDUCATIONAL MANAGEMENT

(MOJEM)

JANUARY 2016, VOLUME 4, ISSUE 1, 44 - 63

E-ISSN NO: $2289-4489$

https://doi.org/10.22452/mojem.vol4no1.4

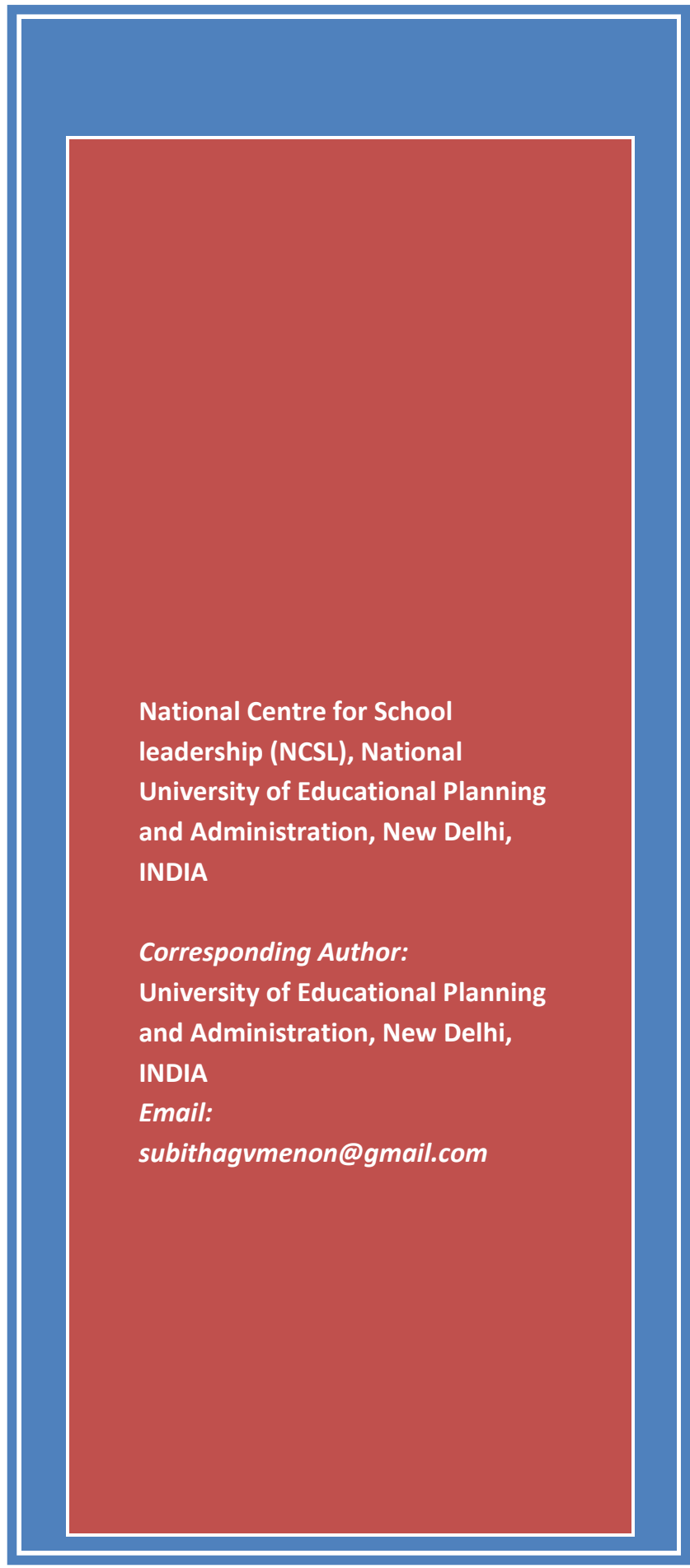

\section{EFFECTIVE SCHOOL LEADERSHIP PROGRAM: A STUDY OF PRACTITIONERS' PERCEPTIONS IN INDIAN CONTEXT}

Subitha. G.V (PhD)

\begin{abstract}
This study on leadership development among school heads in government and aided schools of India investigated the significance of a school leadership development program for the school heads of Odisha and Karnataka as perceived by a specific group of state level practitioners called the State Resource Group (SRG). The school leadership program is a policy initiative funded by the Ministry of Human Resources Development, India and formulated under the National Centre for School Leadership at the National University of Educational Planning and Administration, India. The sample of the study consists of 50 State Resource Group members from Karnataka and Odisha states. Interviews and focus group discussions have been used to collect data for this qualitative study. By highlighting the sample groups' perceptions of challenges of the school heads, lacunae in existing professional development programs and how these lacunae can be addressed, this study would help in addressing key issues and challenges in implementing the school leadership program. Based on the perceptions of the SRG members, the study found that the main challenges faced by school heads included the inability to collaborate and work as a team, inadequate interpersonal skills, lack of content knowledge, political interference in running of the school and inability to deal with context specific challenges. Based on the findings the study identified thrust areas that would inform the curriculum of NCSL school leadership development to help the school heads deal with these challenges
\end{abstract}

Keywords: School leadership development, State Resource Group, School leadership program implementation, School improvement, Education, India 


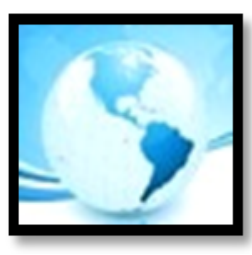

\section{MALAYSIAN ONLINE JOURNAL OF EDUCATIONAL MANAGEMENT (MOJEM)}

\section{INTRODUCTION}

School leadership has recently established a new significance. It has emerged from several decades of being in the shadows of educational administration and management to enjoy its own time in the sun (Harris, 2005). School leadership is slowly being established as the de facto force behind school improvement. It is currently the answer to the fundamental question raised by educationists which is 'how do we improve schools'?

The relationship between high quality leadership and educational outcomes is well documented in numerous research studies. Generations of research on school effectiveness shows that excellent leadership is one of the main factors in high-performing schools (Beare, Caldwall, \&Millikan, 1989; Creemers, 1996; Reynolds, 1991; Sammons, Hillman,\& Mortimore, 1995). According to Harris (2005), researchers in school effectiveness and school improvement have consistently highlighted the importance of leadership in generating better schools (Hargreaves et al., 1998; Hopkins, 2001; Sammons, 1999). Leadership has become synonymous with school effectiveness (Teddlie \& Reynolds, 2000). Largely overlooked in the various reform movements of the past two decades, principals are now regarded as central to the task of building schools that promote powerful teaching learning for all students rather than merely maintaining the status quo (National Policy Board for Educational Administration, 2001;Peterson, 2002)

\section{The Context}

Research studies have confirmed the increasing salience of school leadership in transforming schools and school heads as the prime mover for this transformation. Yet there is a growing concern that the school principal role designed for the industrial age has not changed enough to deal with the complex 21st century challenges. Hence countries are seeking to develop new conditions for school leadership better suited to respond to current and future educational environments. According to Pont, Nusche, and Moorman (2008) as expectations of what school leaders should achieve have changed, so must the definition and task distribution, as well as the levels of training, support and incentives. According to Daresh (2004), no longer can support for the principals be described as a mere frill. Traditional school principal certification and professional development programs have endured criticism (Elmore, 2000; Hess, 2003; Hess \& Kelly, 2007; Levine, 2005; Tucker \& Codding,2002); researchers and policy makers alike have explored new strategies to train new and existing principals (Huff, Preston,\& Goldring, 2013).

Taking together the findings of these research studies it is evident that school leadership development programs are very important for developing 21st century school leaders. This article discusses a school leadership development program for the school heads of government schools of India under a new policy initiative funded by the Ministry of Human Resource and Development (MHRD) and implemented by the National Centre for School Leadership (NCSL) at the National University of Educational Planning and Administration (NUEPA), India. The leadership program is in the process of implementation in 22 states including Odisha and Karnataka.

Before implementing a school leadership program in a given context, gathering an understanding of what the primary stakeholders at the state and district level perceive about the program with respect to "what should be" and "what should not be "would definitely help in improving implementation. Hence the study investigated the perceptions of state level practitioners of Odisha and Karnataka on the school leadership program to be 
implemented in their states. It is assumed that as state level officers they will be aware of the ground realities of the education system in their states and thereby their perceptions on how an exemplar school leadership program can be implemented could inform the curriculum and the training design of the school leadership program while delineating certain guidelines on effective implementation.

\section{Leadership Program's Approach: National Centre for School Leadership (NCSL)}

The National Centre for School Leadership (NCSL), NUEPA, India, recognizes the school as the basic unit of change and the school heads as the prime mover of schools. The Centre, in accordance with its recently developed National Curriculum Framework on School Leadership and the National Programme Design, proposes a 10 day capacity building program for the school heads. The design ensures delivery of the capacity building program and transaction of the curriculum in the States by constituting in each state a critical mass of experts and specialist practitioners called the State Resource Group (National University of Educational Planning and Administration, 2014 , p. 3). The State Resource Group members (SRG) are the prime people who would build the capacity of the school heads in each state. Figure 1 illustrates the design of NCSL-NUEPA school leadership program.

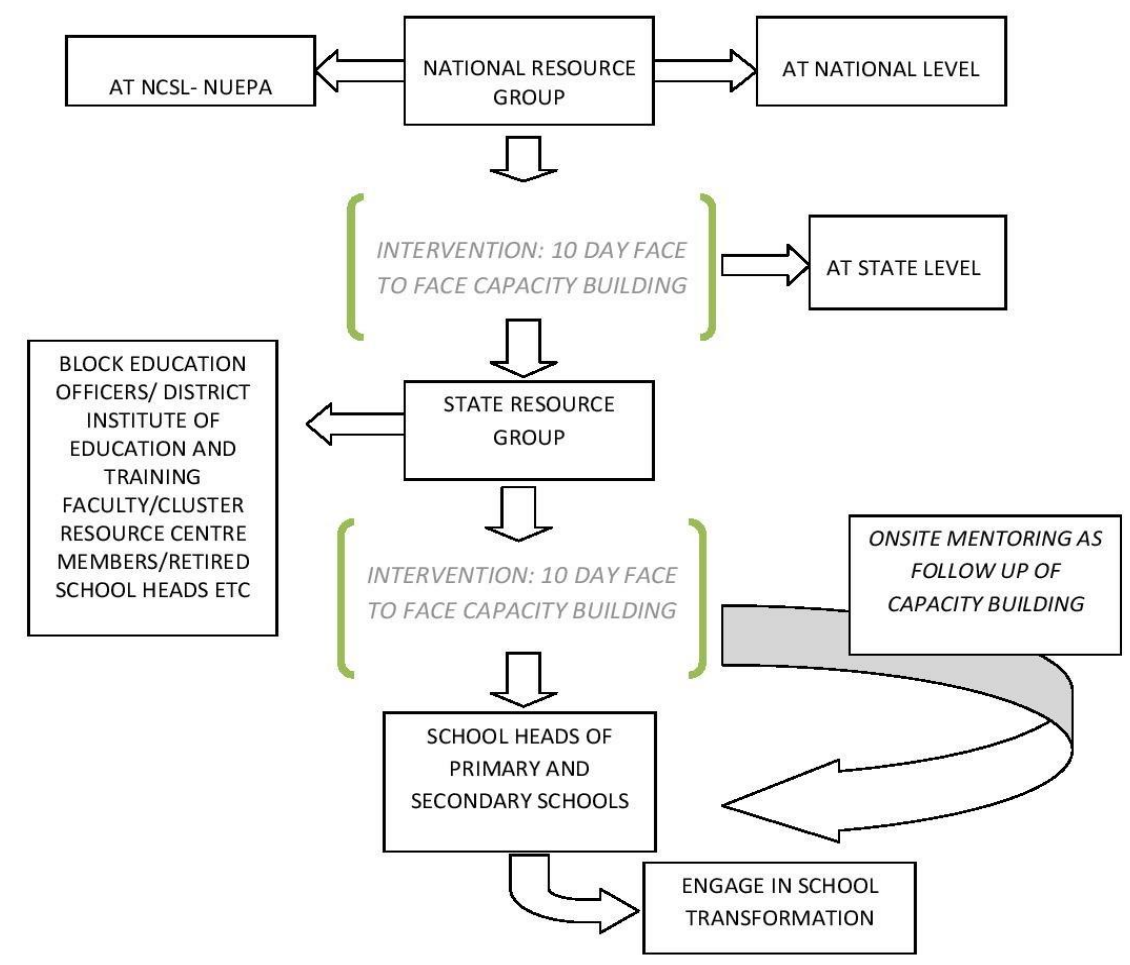

Figure 1. Design of NCSL School Leadership Programme. 


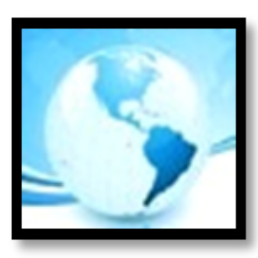

\section{MALAYSIAN ONLINE JOURNAL OF EDUCATIONAL MANAGEMENT (MOJEM)}

The program ,as part of its continuous professional development for the school heads, proposes onsite mentoring to support the school heads in their school transformation initiative. The State Resource Group members will therefore be involved in two challenging tasks namely engaging in the capacity building of the school heads through a 10-day face to face training model and following up through regular onsite mentoring and feedback.

\section{Onsite Mentoring}

In its attempt to provide ongoing support for the development of school heads, the NCSL-NUEPA school leadership program has conceptualized Mentoring as a form of onsite support for the school heads after the 10 day capacity building program. It needs to be emphasized that Mentoring in the program takes on a generic term-- which means that the program design to date does not offer a precise definition of mentoring; neither does it give a clear role description as to what the State Resource Group, as mentors, should actually do in the field. Though the design does provide parameters on the cycle of cluster review meetings and follow up discussions to be conducted by the SRG members after the 10 day face to face capacity building program, yet it does not describe in depth the practice of onsite mentoring. It would not be an overstatement to say that onsite mentoring according to the program holds the same significance as onsite guidance and handholding done mainly through cluster level meetings and school visits. The study therefore discusses the mentoring process using the same lens as onsite guidance. It is not the objective of this article to study the sample groups' perceptions on the detailed process of mentoring like 'How should the mentors be trained?', 'What are the different mentoring strategies to be adopted?' 'How do we evaluate the mentoring process?' and so forth.Table1 illustrates the onsite mentoring phase for the school heads(National University of Educational Planning and Administration, 2014, p. 142).

Table1

Design of Onsite Mentoring for the School Heads

\begin{tabular}{|c|c|c|c|c|c|c|c|}
\hline Month & 1 & 2 & 4 & $\begin{array}{lll}5 & 6 & 7\end{array}$ & 8 & $\begin{array}{lll}9 & 10 & 11\end{array}$ & 12 \\
\hline Intervention & $\begin{array}{l}\text { Capacity } \\
\text { building }\end{array}$ & $\begin{array}{l}\text { Provide On- } \\
\text { site support }\end{array}$ & $\begin{array}{c}\text { Review \& } \\
\text { feedback } \\
\text { workshop } \\
\text { \#1 }\end{array}$ & $\begin{array}{l}\text { Provide On- } \\
\text { site support }\end{array}$ & $\begin{array}{c}\text { Review \& } \\
\text { feedback } \\
\text { workshop } \\
\text { \#2 }\end{array}$ & Peer visits & Retreat \\
\hline Duration & 10 days & $\begin{array}{l}\text { At least once } \\
\text { in } 2 \text { months }\end{array}$ & 2 days & $\begin{array}{l}\text { Twice in } 3 \\
\text { months }\end{array}$ & 2 days & $\begin{array}{l}2 \text { visits in } \\
\text { school per } \\
\text { HM }\end{array}$ & 2 days \\
\hline
\end{tabular}




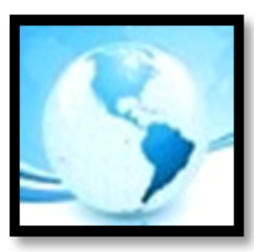

\section{MALAYSIAN ONLINE JOURNAL OF EDUCATIONAL MANAGEMENT (MOJEM)}

\section{RATIONALE FOR THE STUDY}

The current study assumes that the State Resource Group members are the core people from the Education department in each State who can be mobilized to help transform the schools. They are the agency who would eventually become the working team of motivated adults who would play the role of Mentors for the school heads, and would advance the leadership program and take responsibility for guiding the school heads to generate change in schools. This study was timed during the phase before the state resource group members have received the 10 day capacity building program on school leadership from the NCSL resource persons but have not yet conducted the 10 day capacity building of the school heads and follow up of onsite mentoring. The investigator attempts to highlight their perception of the program based on their role as practitioners and as primary stakeholders of the leadership programs in Odisha and Karnataka. Some questions asked: What is their idea of leadership? What according to them are the challenges of the school heads that need to be addressed? Do they consider the leadership program as being beneficial for the school heads to transform their schools? Where according to them is the lacuna in training programs for the school heads at the state/district level? What are the training needs of school heads? What measures should the present leadership training program take to prevent these lacunae? How do they as state level resource persons plan to collaborate and network with the school heads? What is their vision for the child in school?

This article, by responding to these questions, attempts to understand the major issues for consideration while implementing the school leadership program. An understanding of the issues and challenges would help in designing the programs to cater to specific needs of the school heads. Understanding of the issues would also enable reflection and empowerment of the school heads on these issues during the 10 day face to face capacity building program. The perspectives of the State Resource Group Members would also help to chart out certain guidelines for effective implementation of the school leadership program there by ensuring program success and sustainability.

\section{RESEARCH QUESTIONS}

The research was designed to answer the following research questions:

1. What is the perception of the state resource group members with respect to
a. Leadership
b. Quality of State/district level training programs
c. Challenges faced by the school heads
d. Training needs of school heads
e. School leadership as an ideal policy initiative
f. Role as mentors for the school heads
g. Vision for the child

2. What are the major issues in the education system in Odisha and Karnataka that need to be considered for its effective program implementation and to maintenance? 


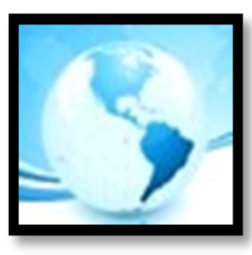

\section{METHODOLOGY}

\section{Research Design}

The study attempted to investigate the significance of a school leadership development program for the school heads of Odisha and Karnataka as perceived by a group of practitioners called the State Resource Group. The study is designed within a qualitative research paradigm. An open ended interview protocol followed by telephonic interviews were used as the main data collection method in this study.

\section{Participants}

A total of 100 State Resource Group (SRG) members were identified by the State Education Department from Odisha. Another 50SRG members from Karnataka were identified by the State Education department. From among this sample of 150 members, 25 from Odisha and 25 from Karnataka were selected through purposive sampling. All the 50 participants were part of a 2-day consultative meeting on school leadership development that was held in their respective states. The consultative meetings were state level meetings held in each state in order to orient the SRG members to the school leadership program with respect to its design and time frame. The SRG members from each state were a mixed group consisting of Cluster Resource Coordinators (CRCs), Block Resource Coordinators (BRCs), faculty from District Institute of Educational Technology (DIET), Block Education Officers (BEOs) and so forth. A few members were faculty members of the Institutes of Advanced Study in Education (IASE) and Colleges of Teacher Education (CTEs).

\section{Instrumentation}

The instrument used for data collection was an open ended 20-item interview protocol designed by the investigator. The interview protocol was divided into 4 parts and contained questions that ascertained the perception of the State Resource persons on certain key areas on school leadership. The first set of questions dealt with sample groups' general perception on 'leadership'. Therefore questions on 'what is leadership' and 'what qualities should the head teacher have to improve schools' were included. The second part dealt with questions specifically meant to capture the sample's perceptions of the school heads' challenges and issues. Therefore questions like 'what are the challenges that the school heads have to face in their schools (systemic and personal); what are the training needs of the school heads? Are school heads the right set of people to champion the school leadership program'; 'Is School leadership an ideal policy initiative to support school heads?' were included. The third set of questions intended to capture the sample's perceptions of the quality of training programs provided to the school heads. Thus questions such as, 'What are the different training programs provided to school heads and what more areas need to be focused on?' 'What is the quality of the state/district based training programs for the school heads that are provided by the state education departments?' were included. The fourth set of questions dealt with the sample's perceptions of mentors and mentoring as a strategy under the school leadership framework. Therefore questions like 'What are the qualities required of mentors?'; 'Who should be mentors and how should they be selected?'; 'What are the personal and professional benefits of being a mentor? "What areas do you need training in to become mentors for the school heads? "What are your strategies for networking with the school heads and other stakeholders? 'What is your vision for the child?' and so forth were included. 


\section{Procedure}

As mentioned earlier, the 50 State Resource Group members selected for the study had participated in the consultative meeting held in the respective states. In her position as the coordinator of school leadership programs in Odisha and Karnataka, the investigator had established good rapport with the 50SRG members. The interview protocol was sent to the participants through e-mail. This was followed up by a phone call to all the participants explaining to them the aims and purpose of the investigation. It was requested that they send back the interview protocol duly filled up in one week.

After the participants had duly submitted their responses, the investigator resorted to telephonic interviews to probe and further clarify their responses. This was done to ensure validity and accuracy of their feedback.

\section{Analysis of Findings}

Analytic strategies included coding of transcribed interview audio files for salient concepts, grouping related codes into broader categories and themes; and creating descriptive summaries. Patterns across categories were explored by writing analytic descriptors. Comparison of patterns of similarities and differences within and across matrices were done to gain a perspective of the ideas expressed by the sample group.

\section{FINDINGS}

The responses of the SRG members to the open ended interview protocol have been grouped under various themes and illustrated. Under each theme the responses of the SRG members from Karnataka and Odisha are described separately.

\section{Defining Leadership}

According to the SRG members of Karnataka, leadership means having a vision and influencing the team to move toward achieving the vision and reaching the goal. The term 'influence', 'vision', 'goal', 'team' and 'collaboration' were recurring terms in the definition of leadership by this group. The following expressions of the sample group confirm this:

'Leadership in the context of school (institution) can be defined as an activity/ability of leading a group of people in an institution and bring intended changes in order to achieve goals and vision'.

'Leadership is all about exercising social influence over others to achieve a commonly agreed goal/set of goals'.

The SRG members of Odisha also described leadership as inspiring the team to achieve the goal. According to one participant:

'Leadership means to lead the team in right way as a result of which the output of the organization will be benefitted'. 


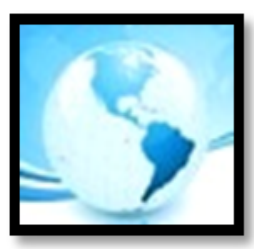

\section{Leadership Qualities Required To Improve Schools}

Table 2 shows the leadership qualities to improve schools as perceived by the sample group of State Resource Group members

Table 2

Leadership Qualities to Improve Schools

\begin{tabular}{ll}
\hline Name of the State & Leadership qualities \\
\hline Karnataka & $\begin{array}{l}\text { 'visionary', 'inspire', 'build teams', 'committed', 'have good communication skills', } \\
\text { 'manage people', 'good interpersonal relationship' }\end{array}$ \\
\hline Odisha & $\begin{array}{l}\text { are 'innovators', 'professionally disposed towards continuous learning', 'good } \\
\text { communicators', 'belief in 'We' and not 'l', 'good management abilities' 'having shared } \\
\text { vision' and 'positive attitude'. }\end{array}$
\end{tabular}

Value based terms such as 'being democratic', 'secularistic', and 'being inclusive' were also used by the sample group from Karnataka and Odisha group as preferred leadership qualities to improve schools.

\section{Challenges Faced By the School Heads}

The school heads from Karnataka and Odisha face a number of systemic and personal challenges. Table 3 illustrates the challenges faced by the school heads of Odisha and Karnataka. 


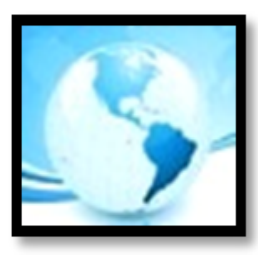

Table 3

Systemic Level and Personal Challenges of School Heads

\begin{tabular}{ll}
\hline $\begin{array}{l}\text { Name of the } \\
\text { State }\end{array}$ & Systemic Level Challenges \\
\hline Karnataka & $\begin{array}{l}\text { Non-cooperation by the teachers, minimum } \\
\text { community participation, heavy workload, non- } \\
\text { availability of resources, lack of knowledge in } \\
\text { administration and data management, lack of } \\
\text { sources to provide new information, frequent } \\
\text { transfers and political interference }\end{array}$
\end{tabular}

Personal Challenges

Feeling of isolation and lack of support from the higher officers, political interference, lack of support from the School Development Management Committee, inability to delegate work, feeling of insecurity. Lack of advocacy skills (to motivate and inspire), inability to manage interpersonal relationship, not much scope for updating one's ideas and lack of technology skills

Odisha
drops number of subject teachers, issue of huge
thereby inability to mentor teachers, poor
attendance of students, lack of standardized
transfer policy, inadequate learning resources,
lack of platform to share productive ideas,
required to work in remote areas, inability to
handle multilingual children and first generation
learners, difficulty in managing schools in
Naxalite dominated areas and minority
dominated area, political interference, and so
forth.

Lack of content knowledge, dealing with the negative attitude of the staff, lack of belief in other teachers' ability, language problem, accountability, fear and insecurity, poor community relationships, heavy workload, and family problems.

\section{Systemic Level Challenges (Karnataka)}

In the case of Karnataka, the most quoted challenge at the systemic level was that when the school heads from elementary schools get promoted to secondary schools, along with increased responsibility they lack the ability to manage the school and support teachers. Two reasons accorded for this happening is lack of content knowledge and lack of academic support from the system level officials. According to a state level practitioner:

'School heads suffer from non-exposure to outside world and new trends. There is a lack of adequate structures in the system to update oneself with the contemporary issues and professional growth'. 


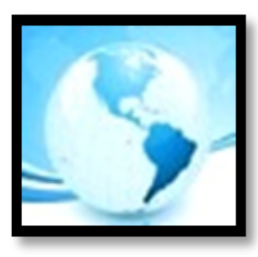

A cluster resource coordinator said that:

'Most of them are not comfortable with technology-a very necessary skill for all. They do not know [how] to handle computers or other technical equipment. Learning at this age is quite minimal.'

\section{Personal Challenges (Karnataka)}

Among the personal challenges, feeling of insecurity, inability to delegate work and lack of advocacy skills were the most quoted challenges. The following expressions of a practitioner confirm this

'Insecurity feeling within is a reason for school headsfor not giving freedom to their colleagues. Hence the school heads keep all the materials, records and equipment under lock and key, to prove that they are the master of their schools'.

'Work delegation does not happen - some school heads have a bias that their colleagues would think that they are incapable; some co-teachers think that it is the duty of the school heads to do all the work.'

'School heads lack advocacy skills to convince the stakeholders to mobilize resources for school development.'

\section{Systemic Level Challenges (Odisha)}

For the SRG members of Odisha relationship with stakeholders especially the SMC was the top most in the list in the category of systemic challenges. The following expression by a participant reflects this.

'The head teachers have to face number of challenges like non-cooperation of staff, dropout among children, poor relationship with School Management Committee, etc'.

\section{Personal Challenges (Odisha)}

Among the personal challenges faced by the school heads in Odisha, lack of content knowledge was considered as a common personal challenge along with dealing with the negative attitude of the staff. The other personal challenges included lack of belief in other teachers' ability, language problem, accountability, fear and insecurity, poor community relationships, heavy workload, and family problems.

\section{School Leadership as an Ideal Policy to Improve Schools}

According to the SRG members of Karnataka, School leadership as a policy can enable the school heads to develop autonomy as there would be a support system in place. It would provide a holistic perspective to the school heads about school and school improvement. It would give clarity about the roles and responsibilities that the school 


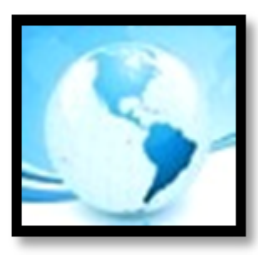

\section{MALAYSIAN ONLINE JOURNAL OF EDUCATIONAL MANAGEMENT (MOJEM)}

heads have to perform in their schools and would also develop in them a sense of ownership. As a policy it will make it mandatory for time, efforts, energy and funds to go to school development. It will enable them to broaden their perspective of school as a learning organization. The following expression of a Block Education Officer confirm this:

'School leadership is not just about the schools. It is about holistic development. It allows the school to move towards excellence and people to give their best. As a policy it will institutionalize, give appropriate structure and make it mandatory for time, efforts, energy and funds to go into school development.'

Regarding perceiving school heads as the ideal people who can championship this program, few SRG members of Karnataka were of the opinion that School heads are indeed the ideal people as they are more connected with the reality of the schools and capable of bringing about innovation and change. They would act as the bridge between the administrators, higher level officers and other stakeholders in the schools. According to a field level functionary:

'HTs (Head teachers) are present in schools, know the environment, resources available, capabilities of the co-teachers, background of the parents and students and can easily fill the gap if they do have the right direction. As they know the local realities they are the ones to easily identify and apply alternative ideas'.

According to the SRG members of Odisha, the leadership program, as a policy, would help to convert schools into a Learning Organization and become centers of excellence. According to one participant: 'School leadership policy may break the traditional way of managing schools by bringing in innovative and constructive ideas'.

The SRG members from Odisha were of the opinion that the school heads are the liaising agency between the school and community and that decision making lies in their hands; they can establish relationship between the various stakeholders, can mentor and coach staff, can influence others in the team, mobilize resources, and act as an agent of change. Therefore they are the ideal people who can championship the school leadership program.

\section{Training Programs for the School Heads}

The state resource group members' perception is that though the school heads go through various training programs, there still are certain important areas in need of capacity building. There is a strong need for providing the school heads with induction training programs. There is also a need for strong monitoring and follow up of all training programs. Table4 illustrates the areas where the school heads of both Karnataka and Odisha require training. 


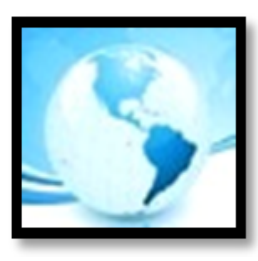

\section{MALAYSIAN ONLINE JOURNAL OF EDUCATIONAL MANAGEMENT (MOJEM)}

Table 4

School Heads Training Needs

Name of the State Training Needs

Karnataka Coaching and mentoring, innovations and risk taking, team building, vision building, creating Professional Learning Communities, documentation skills training in Information and Communication Technology (ICT)

Odisha

Mentoring, formation of PLCs, handling multi-grade classrooms, dealing with children from multiple contexts viz., tribal schools, urban slum and multilingual schools.

Regarding the quality of training programs organized by the state education departments at the state/district level, the state level mentors from Karnataka perceive that they have good content but the program falters at the implementation stage. The training program contents are fragmented and do not help create a holistic approach to school improvement. The programs are not aligned with the challenges faced by the school heads and so the school heads do not find relevance in the real school context. The methodology used is traditional lecture mode, lacks onsite support and addresses too many participants in a single sitting. The following expressions of a State level project officer confirm this:

'The quality of training is ordinary and most training programs end with classroom sessions and do not have hand holding or follow up support. The content of the training is focused on addressing specifics and hence fragmented; it does not help the head teachers in developing a holistic perspective'.

'It is important to identify the needed areas and providing qualitative inputs along with on-site support to enhance their effectiveness in school management.'

According to the SRG members of Odisha, most State level training programs are a onetime engagement without any follow up mechanisms. According to them there is a need to ensure continuous professional development of the school heads through onsite support in the form of mentoring and follow up activities.

\section{Onsite Mentoring}

The design of onsite mentoring is provided in Table1. The State Resource Group members will engage in onsite mentoring for the school heads after the 10 day face to face capacity building program. The process would involve school visits and also participating in review and feedback workshops. According to the sample group, Mentoring as a strategy will help reduce the feeling of isolation among the school heads and provide scope for enhancing confidence and self-esteem. Yet they feel that the process needs an action plan, time to time assessment and a sound implementation strategy. 


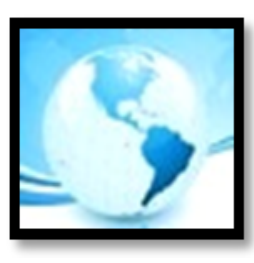

\section{MALAYSIAN ONLINE JOURNAL OF EDUCATIONAL MANAGEMENT (MOJEM)}

\section{Criteria for Selecting Mentors}

With respect to the criteria for selecting mentors in the states, the SRG members of Karnataka have said that the primary criteria for selection of mentors should be that they should be passionate and motivated individuals who can work towards school improvement. They should be practitioners who are field based and in touch with the ground realities of the school. The sample group from Odisha has expressed that mentors should have practical experiences of dealing with issues in the field, and be knowledgeable about the operational aspects of learning.

Table 5 illustrates the criteria proposed by the sample group for the selection of mentors in Odisha and Karnataka

Table 5

Criteria for Selection of Mentors

\begin{tabular}{ll}
\hline Name of the State & Criteria \\
\hline Karnataka & Passionate and motivated individuals, practitioners who are field based, aware of \\
the complexities and the dynamics of the school and the system, have a sound \\
vision of school improvement and change, have updated knowledge of various \\
school leadership theories and should be able to customize their knowledge \\
according to the needs of the school heads, have the qualities of being supportive \\
and patient to attend to the individual and professional needs of the school heads. \\
They could be Cluster Resource Persons, Block Resource Persons, District Institute \\
of Education and Training faculty, local Non- Governmental Organization \\
members, retired officers or educationists.
\end{tabular}

Odisha Good communication skills, ability to empathize and be sensitive to the needs of the school heads, be a role model for the school heads, be democratic, have a mind set to solve problems, be a good listener, able to resolve conflicts, and have a long term vision for school development.

The mentors could be selected from the rank of elementary teachers and secondary school teachers, Block/district Education Officers, DEOs, Assistant Block Education Officers, and so forth.

\section{Sample Groups Own Personal and Professional Development}

Regarding their own personal and professional development which they visualize as mentors, the sample group from Karnataka said that working as a mentor for the HTs would give them scope to learn what works and what does not work in schools, reflect on themselves and evolve to become role models for somebody else, be able to empathize, relate with people and learn new skills in life. The responsibility would enable them to work collaboratively, provide opportunities to manage people and develop organizing skills and networking skills. It will enable them to think in terms of welfare of others rather than thinking about themselves. According to a state level functionary: 


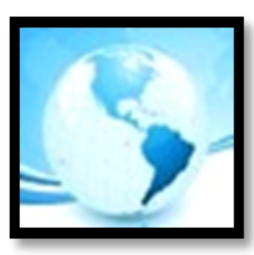

\section{MALAYSIAN ONLINE JOURNAL OF EDUCATIONAL MANAGEMENT (MOJEM)}

'Mentoring will help me focus on issues that are organic and real, to find solutions collectively and collaboratively, to be creative, think out of the box, hand hold the mentee in taking risks and expanding their horizon'

'There is no end to acquire knowledge and it is always a need to sharpen ourselves with refreshing ideas and acquainting with new knowledge and skills. We need to have better and deeper understanding of their routines, practices and challenges. In addition to sharing the existing skills \& knowledge, it is highly essential to give them some new perspectives, knowledge and skills so that they will try to understand their situation in a better way and find appropriate solutions to their problems/challenges.'

Regarding their own personal and professional development as mentors, the SRG members of Odisha expressed that as Mentors, they would be part of a networking group and would thereby be able to acquire new knowledge, skills and positive attitude. The role would give a sense of purpose and personal growth. They would learn to work as a team by connecting with school heads, teachers and community, Parent Teachers Association and children. The role would also instill better respect among the staff. In the long run, they would play a key role in the growth and development of children in schools and also derive better understanding of self as a human being.

\section{Training Needs}

Regarding the areas where they would need more training to become mentors, the sample group from Karnataka expressed that they would need further training in academic leadership, time management skills, communication skills and coaching and mentoring skills.

The sample group from Odisha have expressed that they need more training in areas such as coaching, leadership, and reflective skills, theoretical aspects of school leadership, education theory and child psychology, and ICT skills.

\section{Strategies for Networking with School Heads for Collective Learning}

Regarding the strategies that they would follow to collaborate with the school heads and other stakeholders associated with the schools, the SRG members of Karnataka and Odisha suggested the following:

\section{Strategies for Networking and Collaborative learning- Karnataka}

a. Development of an Individualized Plan: The State Resource Group members suggested that a Personal and Professional Development Plan needs to be drawn for each school head with his/her learning charted out 


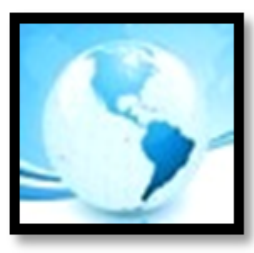

\section{MALAYSIAN ONLINE JOURNAL OF EDUCATIONAL MANAGEMENT (MOJEM)}

b. Workshops and Orientation programs: Based on the school heads' training needs, workshops and orientation programs on specific aspects of school leadership can be organized to improve their knowledge and skills in leadership

c. Involving the Community: The State Resource Group members believed that trustful relationships must be established between schools and communities. Thereby they would ensure that spaces are established within the school system for meetings between school heads and the School Development Management Committee (SDMC).

d. Organizing Community Based Programs: The State Resource Group members suggested that they would guide the school heads to initiate programs in schools where the community also participates in whole school development.

e. Identify Institutions at the District Level: The members were of the opinion that district level institutions (viz., District Institutes of Education and Training) need to be identified whose role would be to help anchor the block and district level leadership programs and also to monitor program implementation

\section{Strategies for Networking and Collaborative Learning-Odisha}

a. Developing an Educational ladder for the School Heads: The State Resource Group members of Odisha suggested that that they would help the school heads to develop Educational ladders so as to enable them to choose a goal, identify focus areas of development, identify problem areas and derive solutions.

b. Periodic Visiting of Schools: The State Resource Group members suggested frequent visits to schools, initiate meeting with school heads and provide feedback for school development, help them generate needs based material and human resources. Visits would also help resource group members to work on attitudinal changes required for the school heads towards school development.

c.Building Trustful Relationships with Community: the state resource group members were of the opinion that the School Management Committees(SMC) and Parent Teacher Associations(PTA) need strengthening to ensure good school-community relationships. Thereby spaces and systems must be created to facilitate regular interaction between the school heads, teachers, PTA and SMC. Spaces need to be provided for weekly/monthly monitoring of the school records by community members. There should be provision for easy access in verification of school related documents. This would ensure transparency and also enable the school to gain trust of the community.

An example of a plan for networking and collective learning as suggested by a practitioner from Karnataka is provided:

'Conducting a Participatory school appraisal to prepare a joint action plan for school improvement. This exercise results in identifying the school improvement needs from different angles by different people teachers, SDMC, parents (men and women separately), school alumni (girls and boys separately), opinion leaders including Grama Panchayath members, students (girls and boys separately).Self-help group 


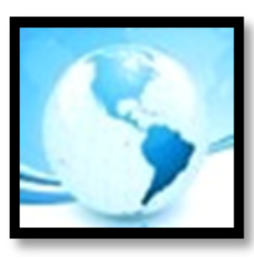

\section{MALAYSIAN ONLINE JOURNAL OF EDUCATIONAL MANAGEMENT (MOJEM)}

members can be looped joined by Anganwadi workers and so forth. During the same exercise a 'chappati' diagram can analyze who are school stakeholders and how far or away they are so that the school head can think of ways and means along with the stakeholders to actively participate in school improvement'.

'Conducting periodic workshops where school heads are properly involved (not signing and then leaving or partial participation) where they pick up appropriate perspectives and are willing to practice developing teachers cohesion, resource mobilization, community participation, school environment (both physical and emotional), learning processes, gender, student leadership and sports'.

'Mentoring them through a 13 week learning and practice approach where supportive supervision is done by mentors including the Cluster Resource Persons and Block Resource Person'..

'Setting up local consultations between the school heads, School Development Management Committee and Gram Panchayat on school improvement programs'.

\section{Vision for Children's' Schooling}

The primary beneficiaries of the school leadership programs are the school children. The State Resource Group members of Karnataka said that children hold a central position in the school system; hence the school should provide a natural environment to enable them to develop to their maximum potential. According to the sample group, children should enjoy learning in schools as they are the custodians of the future. They need to be respected and nurtured at every stage; schools should create an environment for free expression.

According to the SRG members of Odisha, children possess tremendous potentialities which need to be tapped. They need to be provided enough space and opportunity for holistic development. The terms used to explain their vision for the child included 'make school free and open'; 'include all children in learning'; 'provide all children equal opportunities irrespective of caste, creed or gender', 'give each child value and respect', 'make school free from fear' and so forth. Regarding teaching learning process, they observed that children need to be given the freedom to explore, look beyond the textbooks and observe the natural environment, to help them recognize the rights of others and develop into responsible citizens; to question the teacher freely, to develop free thinking and creativity.

\section{IMPLICATIONS OF THE STUDY}

The current study investigates the perceptions of the practitioners from Karnataka and Odisha on school leadership programs as a policy initiative for the school heads. The sample group feels that the school leadership development program is ideal for the school heads as it would help them deal with the issues and challenges they encounter in managing schools. Research studies conducted on challenges faced by school heads have revealed that the main challenges include shortage of financial and material resources, negative attitude of teachers (Makura, 2009), inadequate training, unclear guidelines on their specific roles in school administration, poor relationship between head teacher and teachers, poor community relations resulting from local politics (Kariuki et al., 2012), and not knowing how to involve parents (Preetika \& Priti, 2013). 


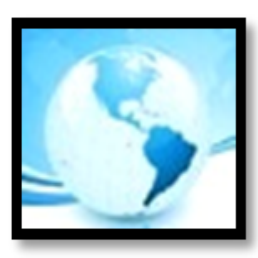

\section{MALAYSIAN ONLINE JOURNAL OF EDUCATIONAL MANAGEMENT (MOJEM)}

In this study, based on the perceptions of the SRG members, the main challenges faced by the school heads can be categorized under the following:

a. Inability to collaborate and work as a team: The challenges include feelings of isolation, lack of support from stakeholders, inability to establish good community relationship, feelings of insecurity and inability to distribute and delegate work

b. Interpersonal skills: non- cooperation by teachers, lack of belief in other teachers' ability, fear and insecurity

c. Lack of content knowledge: lack of ability to lead secondary level schools, lack of knowledge in technology, administration and data management, aggravated by lack of academic support from the higher academic officers such as Cluster Resource Coordinators and Block Education Officers.

d. External interference: Political interference and frequent transfers are also major hurdles in effective school management.

e. Complex context specific challenges of leadership (student population and school location): specific context based issues such as dealing with children in state border areas where multilingual learners dominate, slum areas where there are more first generation learners, children from schools in Naxal dominated areas, and so forth.

The areas of challenges that have been derived inform the curriculum for capacity building by identifying the following thrust areas:

The following Table 6 illustrates the thrust areas that need to be interwoven into the curriculum of school leadership for the capacity building program.

Table 6

Thrust Areas in the Curriculum

\section{Thrust Areas in the Curriculum \\ Perceived Challenges to be solved}

Practice and practical information on teaming and working collaboratively

Solve challenges of isolation, work load, poor relationship with stakeholders, gain content inputs through establishing communities of practice, political interference

\begin{tabular}{ll}
\hline Interpersonal skills & Poor relationship with stakeholders, delegating work \\
\hline $\begin{array}{l}\text { Reflective practices- reflect on personal and } \\
\text { professional self }\end{array}$ & $\begin{array}{l}\text { Inability to believe in other teachers' abilities, fear and } \\
\text { insecurity, family problems }\end{array}$
\end{tabular}

Building community, developing a collaborative Fewer number of subject teachers, minimum community 
mission

Develop strategies to garner resources

Increase communication, develop supportive relationships

Context based real case studies and real world examples of best practices participation, inadequate learning resources,

lack of resource support

feelings of isolation, lack of advocacy skills, insecurity, delegating work, negative staff attitude

Handle the demands of complex context specific challenges of leadership student population, school location

Delegation of work, belief in teachers' abilities, and work load

The data on perceptions of the State Resource Group members provides certain understandings that effectively inform implementation of the school leadership programs. These include:

- The school leadership program should not be a one-time engagement. It should have strong and structured mechanisms for follow up and monitoring

- The program should take a holistic approach and be in tune with the needs of the school heads. It should not be fragmented but should be grounded in the field challenges and realities.

- Learning should follow a collaborative practice and should involve networking with all stakeholders associated with the school

- It should believe in centrality of the child

- The State Resource persons selected should be people who are aware of the ground realities of the school, and possess good communication skills, besides being able to customize their knowledge according to the needs of the school heads.

- State Resource Persons capacity building should include academic leadership, ICT skills, professional learning communities, time management skills, communication skills and coaching and mentoring skills. 


\section{CONCLUSION}

The study attempted to highlight the perception of the State Resource Group members on the NCSL-NUEPA school leadership program. The SRG members are the primary stakeholders of the program. An understanding of their perception of leadership and the challenges faced by the school heads would help create a supportive environment for the school heads and also chart out certain guidelines for ensuring program sustainability and effective program implementation. The challenges stated by the sample group included inability to work as a team, develop interpersonal skills, reflective practice, distributed leadership, and communication skills. These challenges stated would inform the thrust areas of the curriculum for capacity building. The perceptions of the sample have also helped in delineating certain guidelines for effective program implementation including that the program should not be a one-time engagement; should follow a holistic approach and not be fragmented; deal with real life challenges and needs of the school heads; follow collaborative practice and networking; and should believe in the centrality of the child.

\section{REFERENCES}

Beare, H., Caldwell, B.J., \&Millikan, R.H. (1989).Creating an excellent school. London: Routledge.

Creemers, B. (1996). The school effectiveness knowledge base. In D. Reynolds, R. Bollen, B.

Creemers, D. Hopkins, L. Stoll, \& N. Lagerweij (Eds.), Making good schools: Linking school effectiveness and school improvement (pp. 21-35). London: Routledge

Daresh, J. (2004). Mentoring school leaders: Professional promise or predictable problems?

Educational Administration Quarterly, 40(4), 495-517.

Elmore, R. F. (2000). Building a new structure for school leadership. Washington, DC: The Albert Shanker Institute.

Hargreaves, A., Lieberman, A., Fullan, M., \& Hopkins, D. (1998).The international handbook of educational change. Dordrecht: Kluwer.

Harris, Alma.(2005). Leading from the chalk-face: An overview of school leadership. Leadership, 1(1), 73-87. doi: $10.1177 / 1742715005049352$

Hess, F. M. (2003, Fall). Lifting the barrier. Education Next, 12-19.

Hess, F.M.,\& Kelly, A. (2007). Learning to lead: What gets taught in principal -preparation programmes. Teachers College Record, 109(1), 244-274.

Hopkins, D. (2001).School improvement for real. London: Falmer Press. 


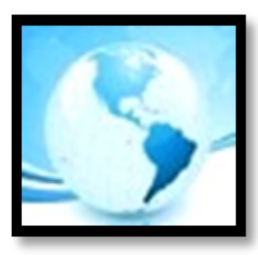

\section{MALAYSIAN ONLINE JOURNAL OF EDUCATIONAL MANAGEMENT (MOJEM)}

Huff, J., Preston, C. E., \& Goldring, E. (2013). Implementation of a coaching program for school principals: Evaluating coaches' strategies and the results. Educational Management, Administration, and Leadership,41(4), 504-526.

Kariuki,Mbugua Zachariah., Majau, Miriti Justine., Mungiria, Muthaa George,\&Nkonge, Reche George. (2012). Challenges faced by Deputy Head teachers in secondary school administration and the strategies they use to tackle them in Imenti South District, Kenya. International Journal of Educational Planning \& Administration, 2(1), 45-53.

Levine. A. (2005).Educating school leaders. New York, NY: The Education School Project.

Makura, A. H. (2009). The Challenges Faced by Female Primary School Heads: The Zimbabwean Experience. Retrieved from http://www.researchgate.net/publication

National Policy Board for Educational Administration. (2001). Recognizing and encouraging exemplary leadership in America's schools: A proposal to establish a system of advanced certification for administrators. Washington, DC: Author.

National University of Educational Planning and Administration.(2014). School leadership development: $A$ handbook. New Delhi, India: Author.

Peterson, K. D. (2002). The professional development of principals: Innovations and opportunities. Educational Administration Quarterly, 38(2), 213-232.

Pont, Beatriz, Nusche, Deborah, \& Moorman, H. (2008).Improving School Leadership-Policy and Practice, 1.Retrieved from http://www.oecd.org/edu/school

Preetika, Badgujar \& Priti,Joshi.(2013). A descriptive study on the challenges faced by the school principals. International Research Journal of Social Sciences,2(5), 39-40

Reynolds, A. J. (1991). Early schooling of children at risk. American Educational Research Journal,28(2), 392-422.

Sammons, P. (1999). School effectiveness: Coming of age in the 21st century. Lisse: Swets \& Zeitlinger.

Sammons, P., Hillman, J., \& Mortimore, P. (1995).Key characteristics of effective schools: A review of school effectiveness research. Report by the Institute of Education, University of London.

Teddlie, C.,\& Reynolds, D. (2000).The International Handbook of School Effectiveness Research. London: Falmer Press.

Tucker, M.S.,\& Codding, J.B. (Eds.) (2002).The principal challenge: Leading and managing schools in an era of accountability. San Francisco, CA: Jossey-Bass. 